in commercial firms. He pointed out that there were many more salesmen and commercial advisers than there were Government advisers, and that the former had to show results in order to keop their jobs. He described the methods of selling which are used, and emphasized that commercial firms have been using 'leader farmers' for some time now. The personal appioach is favoured rather than the mass approach. He pointed out that the less-efficient farmers are reached neither by commercial firms nor by the National Agricultural A.dvisory Service.

Mr. J. Gibbons spoke about the National Agricultural Advisory Service and in particular the problems attendant on advising farmers on an individual basis. On the average, each adviser has 700 farmers in his district, and on an individual basis he cannot do more than 350 visits a year. Advisers like this part of their work, and even though for some kinds of advice the visit might be an uneconomic method, even then it could establish a good relationship between the farmer and the adviser, which would help in any future contacts, even when mass media are to be used. For advice on some topics, where elaborate and detailed discussion were needed, no technique could replace the farm visit. He commented on the need for evaluation of advisory methods and referred to the report of the Agricultural Education Association Committee on Evaluation of Advisory Methods, which had called for more investigations of this nature.
Mr. A. J. Davies also dealt with the National Agricultural Advisory Service, but he was mainly concerned with advising by mass and group mothods. He stressed the necessity for reducing the number of individual visits and quoted the report of an investigation which showed that large changes could be produced with only a relatively small expenditure on mass media. The presentday trend was to favour small discussion groups rather than large meetings, or demonstrations.

There were lively discussions following each paper, and it was clear from these that there were many in the audience who had given much thought to problems concerning the best ways of communicating with farmers, and pioviding them with new information on scientific and technological problems. Nevertheless, although there are basic data about farmers and about what sources of information reach them, there are very few studies which were designed to examine the value of particular sources of information on farming for this purpose.

There is probably no other industry which is so well served with people whose main task it is to bring it up to date and to see that it makes full use of new scientific and technological findings. It is good to know that for those whose job it is to do this, the stage has arrived where expertise is not enough, and that those concerned are now applying research techniques to test the value of their own methods of communication.

D. SHEPPARD

\title{
BARLEY GENETICS
}

$\mathrm{T}$ HE first International Barley Genetics Symposium was held at Wageningen during August 26-30, 1963. The Symposium had been initiated by Dr. H. Lamberts of the Foundation for Agricultural Plant Breeding, Wageningen, and the programme had been discussed between several barley investigators following which an organizing committee had been established in the Netherlands to realize the plans.

The objective of the Symposium was to provide a survey of the present status of research in barley genetics. Several research workers had been invited to present the results of their recent investigations, in connexion with other results and problems in similar fields. In addition, other investigators were able to deliver short papers dealing with their investigations on more specialized topics. The lectures and the shorter contributions were grouped together according to subject. A general discussion was held after each session.

The Symposium began with an address of welcome by Dr. F. E. Nijdam, president of the organizing committee, and was opened officially by an address from Ir. J. G. Wellen, General Director of Agriculture in the Netherlands.

The first session, which dealt with the origin and phylogeny of barley, opened with an address by Bakhteyev (U.S.S.R.). First, the historical development of several discoveries and their related hypotheses and theories were reviewed. In addition, Bakhteyev discussed his own recent investigations with regard to the natural variability of the wild species Hordeum spontaneum. He had found in the southern parts of the U.S.S.R. some specimens of six-rowed wild barley, which he named $H$. langunculiforme. Later this species appeared to be conspecific with tworowed $H$. spontaneum, hence it should be considered as a sub-species of the latter. These findings, Bakhteyev considered, supported the theory of monophyletical descent of all cultivated barley forms from the wild species, H. spontaneum.

The two other contributors in this session arrived more or less at this theory of a monophyletical descent. Takahashi (Japan) came to this conclusion after investi- gating the geographical distribution of several genes, which might have been important in evolution. Zohary (Israel) criticized the suggestion that the origin of the six-rowed brittle barley types, like Aberg's H. agriocrithon and Bakhteyev's $H$. lagunculiforme, followed a possible hybridization between $H$. spontaneum and six-rowed cultivated barleys, which would result in a six-rowed brittle barley. Instead, he claimed that the first wild six-rowed barley has still to be found, and that the descent of barley for the time being must be considered to be monophyletic.

Mutation research was the subject of the second session, which opened with a review by Nilan et al. (United States) of chemical mutagenesis in barley. Investigations in this field have only been undertaken comparatively recently and the first period of screening has only just been completed. Nilan discussed the scoring of direct and indirect biological effects of chemical mutagens, their appearance and the methods of observing them. Furthermore, he gave a review of the various chemical mutagens, their methods of treatment, specific effects, etc. Special attention was directed to the influence of the environmental conditions, both during the treatment and during the observation of the effects.

Hagberg (also for Persson, Sweden), in his address, outlined the practical uses of mutation research in genetics, taxonomy and plant breeding. The use of translocations and the so-called erectoides mutants (short internode length) were discussed in detail. Both types of mutations are being used as genetic markers, while translocations have been further used to break linkage groups or to double special parts of the chromosomes; ert-mutations are being used in investigations of the finest structure of chromosomes or in plant breeding, so as to obtain varieties with short and stiff straw. However, this direct use of mutations in plant breeding is somewhat rare, and generally the mutagenic treatments are given to introduce a high and renewed variability in populations, so as to produce suitable material for selection.

In two contributions, results were presented of com. parative studies of the effects of ionizing radiation and 
chemical mutagens. There are specific differences in the ways in which both types of mutagens act. Favret (Argentina) outlined special investigations which he had carried out on the cytological and physiological effects, while Moës (Belgium) directed attention to work that he had done on dosage effects. Finally, Udda Lundqvist (Sweden) presented the results of her investigations of the production of mutations by irradiation of pollen with $\mathrm{X}$-rays and ultra-violet light.

In the session devoted to chromosome aberrations, macromutations, aneuploidy and polyploidy were considered. Ramage (United States) discussed the translocations, that is, the ways of obtaining them and the various possibilities of using them in genetic research. As genetic markers, they have been used to establish the connexion between linkage groups and chromosomes, so that the number-designations of all the linkage groups had been reconsidered. Translocations are also an important expedient in establishing the exact place of the centromere. Finally, the connexion between translocations and trisomics was treated by Ramage. In the following lecture Tsuchiya discussed aneuploids, in particular the trisomics. These trisomics have been produced from triploids and translocation lines. All seven possible trisomics were obtained; they showed distinet morphological types. The fertility of trisomics appeared to be good; they have been used in cytogenetic research.

The final contribution in this session considered autotetraploids in barley, and was presented by Reinbergs (Canada). Since the discovery of colchicine, many auto. tetraploid barleys have been produced, and their characteristics could be investigated. However, the main problem, a high degree of sterility, has not yet been solved; the sterility is induced, among others, by irregularities during meiosis. Investigations in this field are still being carried out on this problem.

During the session dealing with new genes and linkage investigations a map of the chromosomes of barley was presented. In this map an attempt had been made to place the breaking points of translocations on the genetic linkage map. The map is not yet complete, due to insufficient evidence; however, already a clear picture has been obtained. Robertson (United States) reviewed many new marker genes in the scope of the present status of the linkage investigations. Helgason (Canada) presented linkage data of some morphological characteristics; and Holm (Sweden) talked about linkage invostigations of many new chlorophyll mutants and their possible use in an investigation of the physiological background of chlorophyll formation.

The session on interspecific and integeneric hybrids in the genus Hordeum was rather short; only in one lecture, by Rajhathy et al. (Canada), was this subject treated. After a brief description of the species (about 27) of the genus a description followed of the methods of producing hybrids and of the various hybrids obtained so far in Canada. The interspecific relationships in the genus have been investigated. The cross-barriers between the species are rather severe, hence the production of hybrids is fairly difficult. The use of interspecifics in plant breeding is not yet possible, due to sterility of the hybrids. Further research in this fiold is needed, in particular with regard to the possible importance in breeding for winter hardiness, drought resistance and disease resistance.

The fifth session of the Symposium dealt with disease resistance. Every year, several barley diseases cause tremondous damage to the crop. In the first address. Moseman (United States) reviewed the results obtained so far in the investigation of the gene-for-gene relationship between barley and its powdery mildew fungus, Erysiphe graminis f. sp. hordei. A method has been developed for determining the inheritance of the pathogenicity of the pathogen; it is also possible to locate the genes for resistance. Thus the genetics of the host-pathogen relationship has been established; however, it is time and labour consuming. The results of these investigations have been used in investigations of physiology, histology and cytology of the host-pathogen relationship.

Two more contributions dealt with powdery mildew. Wahl (also for his co-workers, Israel) discussed the specific difficulties involved in this disease in Israel. He directed special attention to the over-summering of the pathogen under rainless conditions and to the part played by the ubiquitous wild species. Baker (Australia) presented the results of a genetic study of possible allelic series of resistance alleles on the Algerian locus in barley.

The two virus diseases, barley yellow dwarf and barley stripe mosaic, were discussed by Schaller (United States). These viruses have their own problems concerning trans. mission by vectors, their ability to infect other crops such as oats and grasses, their virulence and the resistance or tolerance of their hosts. Another virus or virus-like dwarfing disease, 'enanismo', was mentioned by Gibler and Krull (Colombia); the inheritance has been investigated.

Poehlman (United States) discussed the breeding for resistance to loose smut, Ustilago nuda. Zadoks (The Netherlands) gave a description of the use of race nurseries in cereal resistance breeding. This method is a useful tool for race differentiation.

Finally, Moseman gave a review of the present status of plant pathological research on barley in the United States.

In the session entitled "Physiological and Quantitative Genetics", various subjects were grouped together. Olien (United States) opened with a discussion on winter hardiness in barley. This character of a plant is $a_{0}$ complex property; it involves the ability to escape, to modify or to withstand many different types of stress. A new method was described to evaluate the various types of stress by freezing. By this method three principal types of freezing patterns have been identified; however, these different types of freezing frequently occur simulta. neously.

Grafius (United States) presented a geometric scheme for the construction of populations which provide a maximum chance of success in the breeding for yield. The scheme is based on a detailed analysis of the parents which contributed to the constructed population. In the population only a limited number of plants can be selected on the basis of more readily observable traits.

Finally, Wiebe (United States) discussed the contribu. tion of DDT and its analogues to tho genetics and breeding of barley.

Several investigators contributed to the session dealing with breeding techniques and malting quality. Bell (Great Britain) presented a general review of barley breeding techniques, including such topics as mutation breeding, hybridization, selection, resistance breeding, etc., and reviewed more specialized aspects, such as breeding for physiological characters (yield and malting quality). This address helped to bridge the gap between specialized research and practical breeding, because in many cases the relation between these two sides of barley research was involved.

Suneson (United States) in his paper outlined the socalled 'evolutionary breeding', the use of populations in breeding, and a possible economic use of heterosis. In this field 'composite crosses' (bulks of hybrids) are being used and explored, sometimes together with male sterility, to produce hybrid barley for the evaluation of heterosis.

Breeding for malting quality was discussed by various contributors, all of them presenting their own methods and systems or their own recent results with already known methods. Lein (Germany) reviewed the problems and results of the European practical breeders. Some remarks were made about the methods practised in selection for specific properties of malting barley. The interests of breeders, maltsters and brewers were mentioned. 
Whitehouse (also for Whitmore, Great Britain) and Wilten (also for Wijvekate, The Netherlands) described the methods used at their institutes for evaluating the malting quality. The practical uses of these micro-malting tests in genetic experiments and breeding were discussed. Raw (Australia) reviewed the breeding for malting barley in southern Australia; Lekeš (Czechoslovakia) presented a similar review of the problems in his country.

Finally, Gotoh (Japan) described phenotypic expressivity of various genotypes and the use of differences of expressivity in various environments in order to arrive at an efficient selection. Finlay (Australia) presented an investigation of the classification of varieties as to their adaptability to environments. The evaluation of this investigation for selection was discussed.

The closing session dealt with three main subjects. The first concerned the election of a Permanent Barley Committee. This Committee, with Dr. G. A. Wiebe (United States) as president and Dr. R. A. Nilan (United States) as secretary, will have the task of organizing the next barley symposium and of co-ordinating barley research. It was difficult to decide in advance the full task of this Committee; its activities will be made more precise in the near future.
Two resolutions were presented and discussed which had been prepared in small discussion groups of specialists. The first dealt with the "Origin and Phylogeny of Barley". It is proposed to undertake joint investigations and co-ordinate the work in this field: the organization of international expeditions was specially mentioned. The second resolution dealt with "Procedures for the Nomenclature and Handling of Genetic Stocks", where specialists would like to see closer co-operation. A motion was presented concerning the appointment of co-ordinators for maintenance and nomenclature of genetic stocks (for example, genetic markers, translocations, trisomics, resistant lines, autotetraploids, etc.). The stocks will be available to all investigators and any new stock will be sent to collaborators, together with complete information on this stock.

Finally, it was announced that the Proceedings of this Symposium, containing the full text of all papers, discussions and resolutions, would be published some time in 1964 by the Centre for Agricultural Publications and Documentation (PUDOC), Wageningen.

The Symposium was a great success; the organizing committee, with Dr. Lamberts as secretary, earned the appreciation of all participants.

W. LANGE:

\section{SAFETY AND RELIABILITY OF SEA AND AIR TRANSPORT}

\begin{abstract}
A CONFERENCE entitled "The Safety and Reliability of Sea and Air Transport" was held by the British, French and German Institutes of Navigation in the Congress Hall at Eastbourne on May 12, and was attended by some four hundred delegates.

In his presidential address, Dr. G. E. R. Deacon, president of the Institute of Navigation in London and director of the National Institute of Oceanography, Wormley, pointed out that such conferences offered opportunities for specialists from all sides, meeting on level terms, to identify and appraise a problem and research area of wide significance. The results of previous work were beginning to bear fruit. After the last tripartite conference, the Dover Strait Working Group had been formed to look into the desirability of routing at sea in general, with particular reference to the Dover Strait. The Group's recommendations had received overwhelming support from master mariners, and had recently been accepted by the Maritime Safety Committee of the Intergovernmental Maritime Consultative Organization, and the Maritime Safety Committee was proposing that as early as possible Governments should be asked to advise their ships to follow the routes suggested by the Working Group.
\end{abstract}

This was quite speedy action compared with the start of the North Atlantic routes, and Dr. Deacon commented that a recent biography of Matthew Fontaine Maury, U.S. Navy, was a good reminder of their early history. After 300 lives had been lost in a collision between the U.S. steamer Arctic and the French steamer Vesta in thick fog in 1854, a prominent shipowner in Boston had consulted Maury on the practicability of defining lanes in which steamers would be required to travel. This was soon followed by a formal request from a group of underwriters, shipowners and merchants, and Maury drew up a scheme which was published in 1855. Many steamships used the scheme and at least one company advertised that travellers could trust in the safety of its ships because they followed Mrury's steam lanes. When the Ville de Havre was lost in 1874 The Times had commented that "If she had followed Maury's steam lanes this terrible loss of life and ship would have been avoided". It was not until 1889 that a marine conference at Washington considered the question of sea lanes, and not until 1898 that a plan was agreed upon.
The findings of the present conference, Dr. Deacon pointed out, had no official authority, but the considered view of a representative group of specialists, speaking rather more freely in Eastbourne than they might in their own capital cities, must be to everyone's advantage. The programme of the conference covered a wide range of subjects, but with many a common theme. When two sailors debated a difficult point it might well be that an airman would supply the answer, and the seamen would no doubt profit from seeing some of their rather unyielding problems translated into the more rarefied environment of high-speed flight. In many branches of science and technology the increasing necessity for better and more economical performance meant that it was necessary to concentrate on the second-order terms-the sort of things that the conference had felt able to neglect in its first and very serviceable approach. In all-weather landing, for example, the human pilot must to an increasing extent be assisted by automatic techniques. The same was true for the special problems of supersonic flight where the information that instruments provide must be extensively 'processed' if the human pilot was to act on it fast enough. In the sea supplementary methods and refined techniques could be devised, which, although at first appearing to be too novel or elaborate for ordinary use, would permit advances to be made with the times as safely and reliably as all forms of transport.

The 'business' part of the conference was divided into thirteen consecutive sessions which dealt with many diverse aspects of navigation. Papers presented included insurance and the collision problem at sea; recommended routes in congested areas; the separation of aircraft and regulation of air traffic; all-weather landing; radar and the human operator; marine radar development; bridge design and human factors; shipborne communications and nav-aids; the regularity of traffic flow on inland waterways; meteorological factors in supersonic flight, etc. Contributors, while coming mainly from Britain, France and Germany, also included representatives from the United States, the Netherlands and Italy.

At the end of the conference there was general agree. ment that immediate measures should be taken to enable ships to navigate through heavily congested areas with more efficiency and a higher degree of safety. The three Institutes, the Institute of Navigation, Institut Français 